Utah State University

DigitalCommons@USU

$1-1-2007$

\title{
Transmission Efficiency of an Aerodynamic Focusing Lens \\ System: Comparison of Model Calculations and Laboratory \\ Measurements for the Aerodyne Aerosol Mass Spectrometer
}

\author{
Peter S. K. Liu \\ Rensheng Deng \\ Kenneth A. Smith \\ Leah R. Williams \\ John T. Jayne \\ Manjula R. Canagaratna
}

See next page for additional authors

Follow this and additional works at: https://digitalcommons.usu.edu/sdl_pubs

\section{Recommended Citation}

K., Peter S. Liu; Deng, Rensheng; Smith, Kenneth A.; Williams, Leah R.; Jayne, John T.; Canagaratna, Manjula R.; Moore, Kori; Onasch, Timothy B.; Worsnop, Douglas R.; and Deshler, Terry, "Transmission Efficiency of an Aerodynamic Focusing Lens System: Comparison of Model Calculations and Laboratory Measurements for the Aerodyne Aerosol Mass Spectrometer" (2007). Space Dynamics Lab Publications. Paper 82.

https://digitalcommons.usu.edu/sdl_pubs/82

This Article is brought to you for free and open access by the Space Dynamics Lab at DigitalCommons@USU. It has been accepted for inclusion in Space Dynamics Lab Publications by an authorized administrator of DigitalCommons@USU. For more information, please contact digitalcommons@usu.edu.

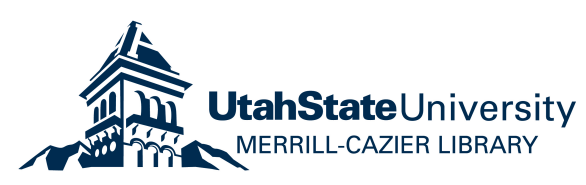




\section{Authors}

Peter S. K. Liu, Rensheng Deng, Kenneth A. Smith, Leah R. Williams, John T. Jayne, Manjula R. Canagaratna, Kori Moore, Timothy B. Onasch, Douglas R. Worsnop, and Terry Deshler 
This article was downloaded by: [Utah State University Libraries]

On: 25 March 2015, At: 11:41

Publisher: Taylor \& Francis

Informa Ltd Registered in England and Wales Registered Number: 1072954 Registered office: Mortimer House, 37-41 Mortimer Street, London W1T 3J H, UK

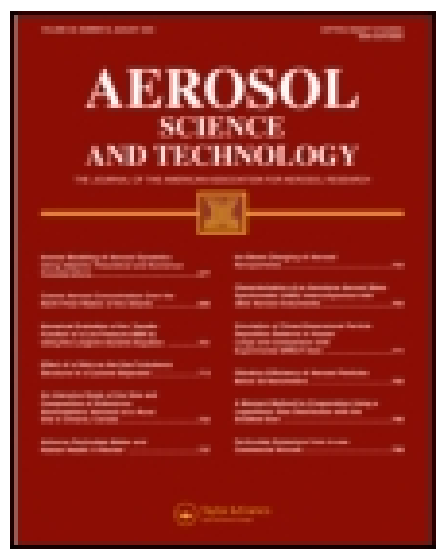

\title{
Aerosol Science and Technology
}

Publication details, including instructions for authors and subscription information:

http:// www.tandfonline.com/loi/ uast20

\section{Transmission Efficiency of an Aerodynamic Focusing Lens System: Comparison of Model Calculations and Laboratory Measurements for the Aerodyne Aerosol Mass Spectrometer}

\author{
Peter S. K. Liu ${ }^{\text {a b }}$, Rensheng Deng ${ }^{c}$, Kenneth A. Smith ${ }^{c}$, Leah R. Williams ${ }^{d}$, J ohn T. Jayne \\ ${ }^{d}$, Manjula R. Canagaratna ${ }^{d}$, Kori Moore ${ }^{d e}$, Timothy B. Onasch ${ }^{d}$, Douglas R. Worsnop ${ }^{d} \&$ \\ Terry Deshler ${ }^{a}$ \\ ${ }^{a}$ Department of Atmospheric Science, University of Wyoming, Laramie, Wyoming, USA \\ ${ }^{b}$ Now at: Cloud Physics and Severe Weather Research Section, Science and Technology \\ Branch, Environment Canada, Ontario, Canada \\ ' Department of Chemical Engineering, Massachusetts Institute of Technology, Cambridge, \\ Massachusetts, USA \\ ${ }^{\mathrm{d}}$ Center for Aerosol and Cloud Chemistry, Aerodyne Research, Inc. , Billerica, \\ Massachusetts, USA \\ ${ }^{\mathrm{e}}$ Now at: Space Dynamics Laboratory, Logan, Utah, USA \\ Published online: $06 \mathrm{~J}$ ul 2007.
}

To cite this article: Peter S. K. Liu, Rensheng Deng, Kenneth A. Smith, Leah R. Williams, J ohn T. Jayne, Manjula R. Canagaratna, Kori Moore, Timothy B. Onasch, Douglas R. Worsnop \& Terry Deshler (2007) Transmission Efficiency of an Aerodynamic Focusing Lens System: Comparison of Model Calculations and Laboratory Measurements for the Aerodyne Aerosol Mass Spectrometer, Aerosol Science and Technology, 41:8, 721-733, DOI: 10.1080/02786820701422278

To link to this article: http:// dx. doi.org/ 10.1080/02786820701422278

\section{PLEASE SCROLL DOWN FOR ARTICLE}

Taylor \& Francis makes every effort to ensure the accuracy of all the information (the "Content") contained in the publications on our platform. However, Taylor \& Francis, our agents, and our licensors make no representations or warranties whatsoever as to the accuracy, completeness, or suitability for any purpose of the Content. Any opinions and views expressed in this publication are the opinions and views of the authors, and are not the views of or endorsed by Taylor \& Francis. The accuracy of the Content should not be relied upon and should be independently verified with primary sources of information. Taylor and Francis shall not be liable for any losses, actions, claims, proceedings, demands, costs, expenses, damages, and other liabilities whatsoever or howsoever caused arising directly or indirectly in connection with, in relation to or arising out of the use of the Content.

This article may be used for research, teaching, and private study purposes. Any substantial or systematic reproduction, redistribution, reselling, loan, sub-licensing, systematic supply, or distribution in any form to anyone is expressly forbidden. Terms \& Conditions of access and use can be found at http:// www.tandfonline.com/page/terms-and-conditions 


\title{
Transmission Efficiency of an Aerodynamic Focusing Lens System: Comparison of Model Calculations and Laboratory Measurements for the Aerodyne Aerosol Mass Spectrometer
}

\author{
Peter S. K. Liu, ${ }^{1,2}$ Rensheng Deng, ${ }^{3}$ Kenneth A. Smith, ${ }^{3}$ Leah R. Williams, ${ }^{4}$ \\ John T. Jayne, ${ }^{4}$ Manjula R. Canagaratna, ${ }^{4}$ Kori Moore, ${ }^{4,5}$ Timothy B. Onasch, ${ }^{4}$ \\ Douglas R. Worsnop, ${ }^{4}$ and Terry Deshler ${ }^{1}$ \\ ${ }^{1}$ Department of Atmospheric Science, University of Wyoming, Laramie, Wyoming, USA \\ ${ }^{2}$ Now at: Cloud Physics and Severe Weather Research Section, Science and Technology Branch, \\ Environment Canada, Ontario, Canada \\ ${ }^{3}$ Department of Chemical Engineering, Massachusetts Institute of Technology, Cambridge, \\ Massachusetts, USA \\ ${ }^{4}$ Center for Aerosol and Cloud Chemistry, Aerodyne Research, Inc., Billerica, Massachusetts, USA \\ ${ }^{5}$ Now at: Space Dynamics Laboratory, Logan, Utah, USA
}

\begin{abstract}
The size-dependent particle transmission efficiency of the aerodynamic lens system used in the Aerodyne Aerosol Mass Spectrometer (AMS) was investigated with computational fluid dynamics (CFD) calculations and experimental measurements. The CFD calculations revealed that the entire lens system, including the aerodynamic lens itself, the critical orifice which defines the operating lens pressure, and a valve assembly, needs to be considered. Previous calculations considered only the aerodynamic lens. The calculations also investigated the effect of operating the lens system at two different sampling pressures, $7.8 \times 10^{4} \mathrm{~Pa}(585$ torr $)$ and 1.0 $\times 10^{5} \mathrm{~Pa}$ (760 torr). Experimental measurements of transmission efficiency were performed with size-selected diethyl hexyl sebacate (DEHS), $\mathrm{NH}_{4} \mathrm{NO}_{3}$, and $\mathrm{NaNO}_{3}$ particles on three different AMS instruments at two different ambient sampling pressures $(7.8 \times$ $10^{4} \mathrm{~Pa}, 585$ torr and $1.0 \times 10^{5} \mathrm{~Pa}, 760$ torr). Comparisons of the measurements and the calculations show qualitative agreement, but there are significant deviations which are as yet unexplained. On the small size end $(30 \mathrm{~nm}$ to $150 \mathrm{~nm}$ vacuum aerodynamic diameter), the measured transmission efficiency is lower than predicted. On the large size end ( $>350 \mathbf{n m}$ vacuum aerodynamic diameter)
\end{abstract}

Received 21 July 2006; accepted 26 April 2007.

The experiments at the University of Wyoming were performed in the aerosol laboratory developed with support from the W.M. Keck Foundation and were partially supported by NSF grant \# ATM0441836. Work performed at Aerodyne Research, Inc. was supported by the NSF Small Business Innovation Research Program, contract \#0216220. Work at MIT was supported by the Singapore-MIT Alliance and by USEPA grant \#RD-83107701-0. K. Moore was supported by the USDOE GCEP SURE program. The Aerodyne authors acknowledge valuable discussions with T. S. Bates.

Address correspondence to Leah R. Williams, Aerodyne Research, Inc., 45 Manning Rd. Billerica, Massachusetts 01821-3976, USA. E-mail: Williams@aerodyne.com the measured transmission efficiency is greater than predicted at $7.8 \times 10^{4} \mathrm{~Pa}(585$ torr) and in good agreement with the prediction at $1.0 \times 10^{5} \mathrm{~Pa}$ (760 torr).

\section{INTRODUCTION}

Aerodynamic particle focusing lenses are frequently used in instrumentation designed to measure particulate properties in both the laboratory and in the field. They have the capability of efficiently separating particles from the gas phase and delivering the particles in a narrow beam into high vacuum. Thus, it is natural to link these lenses to particle mass spectrometers, and a number of aerosol mass spectrometers have been developed which use aerodynamic lens systems (Gard et al. 1997; Jayne et al. 2000; McMurry 2000; Murphy and Thomson 1997; Schreiner et al. 1999; Su et al. 2004; Zelenyuk and Imre 2005; Ziemann et al. 1995). Understanding the transmission efficiency of these systems is important with respect to quantifying the overall performance of an aerosol mass spectrometer. Lens systems have been investigated via numerical calculations (Liu et al. 1995a; Wang et al. 2005a; 2005b; Zhang et al. 2002; 2004), but few studies have focused on comparing the models to actual performance (Jayne et al. 2000; Liu et al. 1995b; Schreiner et al. 1999; Tobias et al. 2000). The work presented here compares model and measurement results and is motivated by the need to understand the efficiency of the lens system used on the Aerodyne Aerosol Mass Spectrometer (AMS) for quantifying aerosol particle measurements. The results presented here are specific to the Aerodyne AMS configured with the standard lens system, but can be generalized to other similar systems. 
The Aerodyne AMS systems are widely used to measure real-time information on size-resolved mass loadings for nonrefractory chemical components in ambient aerosol particles. The AMS has been described in detail by Jayne et al. (2000) and Jiménez et al. (2003). Techniques of data interpretation to quantify aerosol mass are described in Allan et al. (2003a, 2003b). Aerosol particles are introduced into the AMS through a critical orifice at a flow of about $1.4 \mathrm{~cm}^{3} \mathrm{~s}^{-1}$ and focused into a narrow beam by an aerodynamic lens. Particles exiting the aerodynamic lens are accelerated to different terminal velocities depending on the particle size, shape and density. The particles are vaporized on a heated surface, nominally set to $600^{\circ} \mathrm{C}$. Vapor from the non-refractory components of the particles is ionized using standard $70 \mathrm{eV}$ electron impact ionization, and the resulting mass-to-charge ratios $(\mathrm{m} / \mathrm{z})$ for positive ions are analyzed by a quadrupole (or time-of-flight) mass spectrometer.

The AMS operates in two modes, mass spectrum (MS) mode and particle time-of-flight (PToF) mode (Jiménez et al. 2003). The transmission of the beam to the particle detector can be modulated with a mechanical chopper that operates at $100-150 \mathrm{~Hz}$. In MS mode, the quadrupole mass spectrometer is scanned (typically $m / z 1$ to 300 ) with the chopper out of the particle beam to obtain an ensemble averaged mass spectrum of the sampled aerosol. Signals from the ionization of background gases in the detection region are accounted for by subtracting the background mass spectrum obtained with the chopper blocking the particle beam. In the PToF mode, the quadrupole steps through several pre-selected ion fragment masses as the chopper modulates the particle beam.

In order to quantify the AMS measurement of size-resolved chemical composition, the overall collection efficiency $(C E)$ of the AMS must be known. From laboratory and field studies, several factors have been identified that influence $C E$. The transmission efficiency of the inlet system as a function of particle size, $E_{L}\left(d_{v a}\right)$, is defined as the fraction of particles that pass through the critical orifice and lens and impact the vaporizer, assuming spherical particles, where $d_{v a}$ is the vacuum aerodynamic diameter. The collection efficiency can be decreased in the case of non-spherical particles by spreading of the particle beam in the vacuum chamber so that some of the particles miss the vaporizer. The shape transmission factor, $E_{S}\left(d_{v a}\right)$, is defined as the fraction of irregularly shaped particles impacting the vaporizer, relative to spheres of the same $d_{v a}$ (Huffman et al. 2005). In addition, the collection efficiency can be decreased by bouncing of particles from the vaporizer surface before vaporization and detection, $E_{B}\left(d_{v a}\right)$, particularly for solid particles such as $\left(\mathrm{NH}_{4}\right)_{2} \mathrm{SO}_{4}$. The overall collection efficiency, $C E\left(d_{v a}\right)$, is the product of these terms, $E_{L}\left(d_{v a}\right) \times E_{B}\left(d_{v a}\right) \times E_{S}\left(d_{v a}\right)$, for particles of a given size and type. A mass-based measure of $C E$ has been defined previously based on the fraction of total mass collected by the AMS as compared to other instrumentation (see, for example, Allan et al. 2004; Drewnick et al. 2003), but this does not take into account the size dependence of the terms in $C E$.
For many atmospheric measurements of ambient particulate matter, using a size-independent $C E$ works well (Canagaratna et al. 2007; Drewnick et al. 2003; Takegawa et al. 2005). However, in some situations, such as when nucleation mode $(<50 \mathrm{~nm}$ diameter) particles are present, comparisons between AMS and scanning mobility particle sizer (SMPS) data (e.g., in Pittsburg, PA in 2002 (DeCarlo et al. 2007) and in the Gulf of Maine in 2004 (Quinn et al. 2006)), suggest that an understanding of the AMS transmission efficiency as a function of particle size is essential if the total ambient mass is to be correctly determined.

This article presents new numerical calculations and experimental measurements of size-dependent $E_{L}$. The design of the inlet system for the AMS has been optimized for maximum particle transmission in the $d_{v a}$ range of $30-1000 \mathrm{~nm}$, relevant for measurements of ambient atmospheric aerosol mass loadings. $E_{L}$ drops off at smaller sizes due to a lack of the inertia required to achieve focusing and due to Brownian motion in the region downstream of the last aperture of the lens. At larger sizes, $E_{L}$ drops off due to impaction losses associated with an excess of particle inertia. Model calculations have been performed previously for this lens system (Zhang et al. 2002, 2004), but experimental verification of the model calculations has not been published.

\section{COMPUTATIONAL FLUID DYNAMICS MODELING OF THE AERODYNAMIC LENS SYSTEM}

The lens system used in the AMS is based on that described by Liu et al. (1995a, 1995b) and was modified following the work of Zhang et al. $(2002,2004)$ leading to an overall shorter lens length of $177.8 \mathrm{~mm}$. In this work we make a distinction between the aerodynamic lens assembly and the lens system. The lens system is shown in Figure 1a and consists of three separate components, the critical orifice mounting assembly, the valve body and the

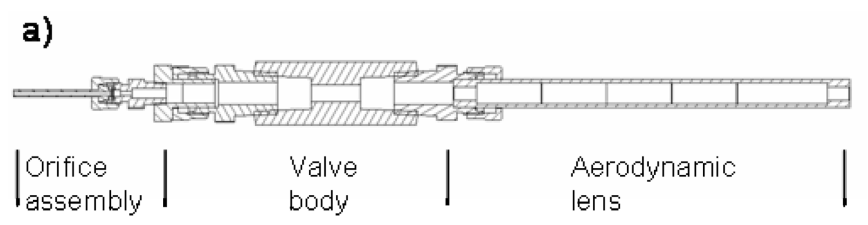

b)

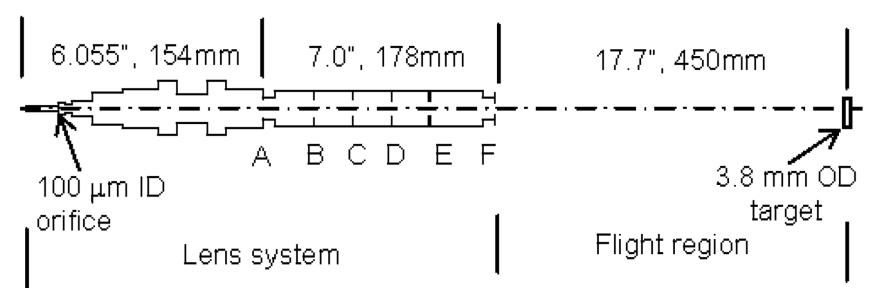

FIG. 1. (a) Drawing of the lens system which is composed of the critical orifice assembly, the valve body and the aerodynamic lens. (b) Structure used in the FLUENT simulations, including the lens system, particle flight region, and target/vaporizer. The diameters of apertures A-F are given in Table 1 . 
aerodynamic lens assembly. It is the combination of these three components that controls the overall particle transmission.

The number of sampled particles that actually reaches the particle vaporizer is not only a function of the lens system but also a function of the distance from the lens exit to the vaporizer $(450 \mathrm{~mm})$ and the diameter of the vaporizer $(3.8 \mathrm{~mm})$. This defines a collection angle of $8 \mathrm{mrad}$. The overall performance of the AMS in terms of $E_{L}$ must account for the lens system and the collection angle.

Computational fluid dynamics (CFD) modeling of the lens system shown in Figure 1a has been performed using FLUENT (Fluent 2003). The calculations addressed several issues regarding the lens system and its coupling to the AMS vacuum chamber. These included investigating (1) the difference between the combined lens system and the lens assembly alone, (2) the difference between modeling the entire system versus modeling separate components and multiplying the results, (3) the effects of Brownian motion on broadening the particle beam in the lens system, (4) the effect of operating at ambient pressures other than one standard atmosphere, (5) the effect of small variations in the actual diameters of the lens apertures, and (6) the effect of modifying the geometry of the critical orifice mounting assembly. The model results for topics 1, 2, and 3 are presented below, followed by a comparison with laboratory measurements of the transmission efficiency for topics 4, 5, and 6 .

The CFD modeling is performed by first calculating the gas flow field. Particles are then injected into the gas flow field and their trajectories are calculated. The transmission efficiency as a function of particle diameter, $E_{L}$, is calculated as the fraction of particles that pass through the lens system and impact the target/vaporizer. Spherical particles with unit density are used in the calculations. A schematic of the structure used for the calculations is shown in Figure $1 \mathrm{~b}$ and includes the lens system, the particle flight region and the target/vaporizer. The diameters of the lens apertures are given in Table 1. Within the AMS community, this lens is referred to as the standard lens.

Figure 2 shows the calculated pressure within the lens system. Starting from an external ambient pressure of $1.0 \times 10^{5} \mathrm{~Pa}$ (760 torr), there is a large pressure drop across the $100 \mu \mathrm{m}$ diameter critical orifice (SPI, Pb-100) to approximately $173 \mathrm{~Pa}(1.3$ torr). On the AMS instrument, a $0-10$ torr range ( $0.5 \%$ accuracy) gauge is used to monitor the lens inlet pressure. The location of

\section{TABLE 1}

Nominal and measured dimensions of lens apertures in the University of Wyoming AMS. Refer to Figure $1 \mathrm{~b}$ for location of apertures. The thickness of apertures B-E is $0.25 \mathrm{~mm}$. Apertures $\mathrm{A}$ and $\mathrm{F}$ are $10 \mathrm{~mm}$ long. The apertures are separated by 30 -mm long spacers

\begin{tabular}{lcccccc}
\hline Aperture & A & B & C & D & E & F \\
\hline Measured ID (mm) & 5.13 & 4.75 & 4.42 & 4.22 & 3.91 & 2.92 \\
Nominal ID (mm) & 5.00 & 4.80 & 4.50 & 4.30 & 4.00 & 3.00 \\
\hline
\end{tabular}

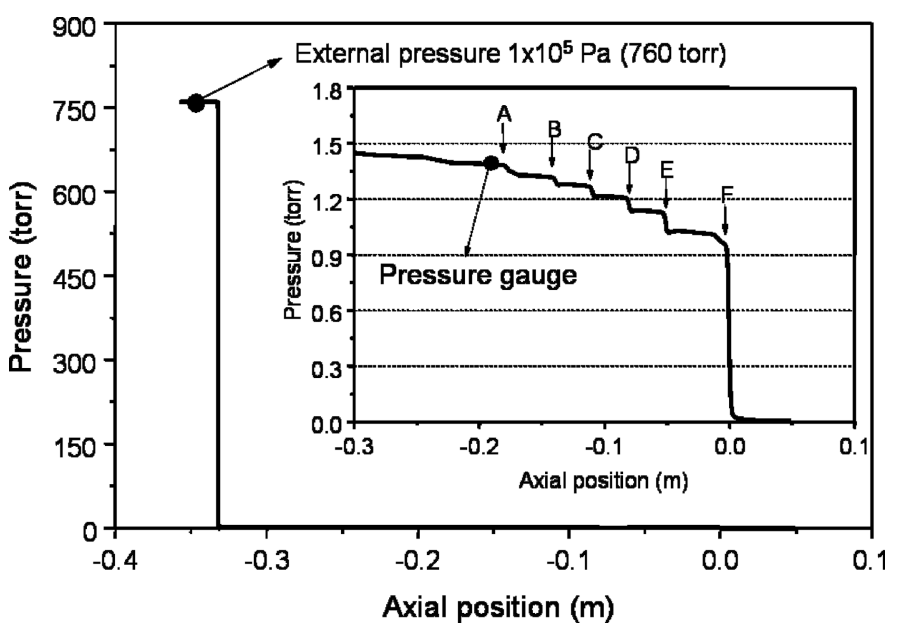

FIG. 2. Calculated pressure in the aerodynamic lens system. The inset expands the low-pressure region. The point indicated in the inset shows the location of the pressure measurement in the AMS. The calculated pressure is $177 \mathrm{~Pa}(1.33$ torr) and agrees well with the measured pressure of $173 \mathrm{~Pa}$ (1.30 torr). Axial position of zero indicates the exit of the aerodynamic lens where the background pressure is $<0.13 \mathrm{~Pa}\left(10^{-3}\right.$ torr $)$.

this pressure measurement is shown in Figure 2. Good agreement is observed between the calculated (177 $\mathrm{Pa}, 1.33$ torr) and measured pressure (173 Pa, 1.30 torr) for an external (ambient) pressure of $1.0 \times 10^{5} \mathrm{~Pa}$ (760 torr). The calculated gas flow rate (74 sccm at $273 \mathrm{~K}$ and 760 torr) is in good agreement with the measured flow rate $(82 \mathrm{ccm}$ at $293 \mathrm{~K}$ or $76 \mathrm{sccm})$. The calculated particle velocities at the exit of the lens are in good agreement with measured particle velocities in the AMS.

The model calculations were performed at two different ambient pressures, $7.8 \times 10^{4} \mathrm{~Pa}\left(585\right.$ torr) and $1.0 \times 10^{5} \mathrm{~Pa}(760$ torr) to match the ambient pressures for the two sets of experimental data presented below. At $7.8 \times 10^{4} \mathrm{~Pa}$ (585 torr), the calculated pressure at the entrance to the lens is $151 \mathrm{~Pa}(1.13$ torr) and the measured value is $153 \mathrm{~Pa}$ (1.15 torr).

\section{Transmission Efficiency for the Lens System vs. Separate Components}

Figure 3 presents CFD results for the lens assembly by itself, the critical orifice plus valve assembly and the combined lens system. These calculations were performed for conditions of 1.0 $\times 10^{5} \mathrm{~Pa}$ (760 torr) with a $100 \mu \mathrm{m}$ diameter critical orifice, and do not include the effects of Brownian motion. The result for the lens assembly by itself (line with squares in Figure 3 ) shows a $100 \%$ transmission window from approximately 60 to $400 \mathrm{~nm}$. The dip in transmission at about $30 \mathrm{~nm}$ was previously observed by Zhang et al. (2004) and is associated with particle losses at the final lens aperture (also referred to as the nozzle).

Calculations on the orifice plus valve assembly are also shown in Figure 3 (line with circles). Note that the plotted $E_{L}$ for this case is the fraction of particles that exit this assembly, not the fraction of particles that would reach the detector. In the calculation, the boundary condition is such that if the particle hits the 


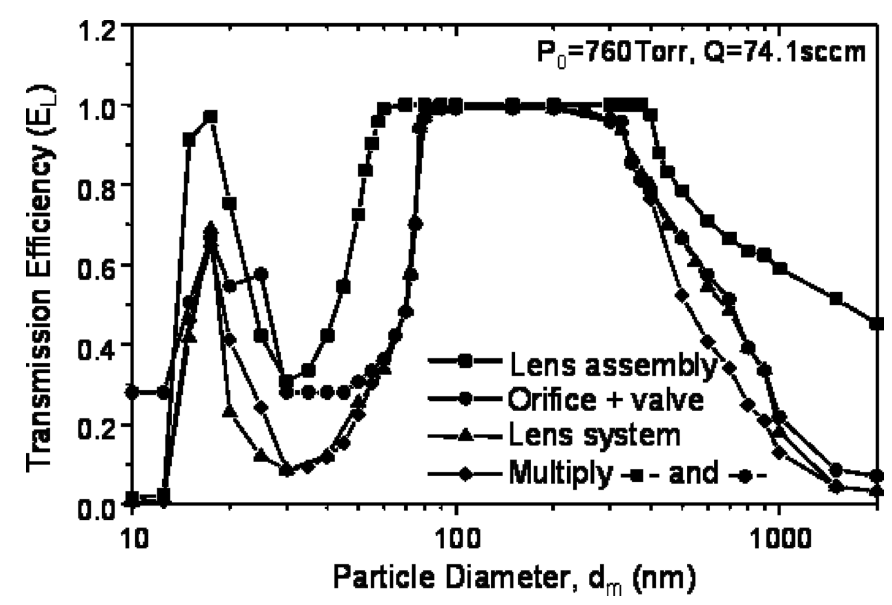

FIG. 3. Calculated transmission efficiency $\left(E_{L}\right)$ for the lens assembly only (squares), the critical orifice plus valve assembly (circles), and the complete lens system (triangles). The line denoted by diamonds shows the $E_{L}$ obtained by multiplying the lens assembly result and the orifice plus valve result. $Q$ is the flow rate through the lens.

wall it is removed. In actuality, this may not be true. Some particles could rebound from a collision and get re-entrained with the gas flow. It can be seen that the orifice-valve assembly has a narrower transmission window than the lens. Thus, it is the controlling element in the lens system and determines both the upper and lower limits of the particle size that can be transmitted through the lens system. This is an important result. In previous model calculations of the AMS transmission efficiency, only the aerodynamic lens assembly was considered (Zhang et al. 2004).

Figure 3 shows the overall transmission of the lens system calculated in two different ways. The line with diamonds shows the product of the lens assembly and the orifice-valve assembly calculations, while the line with triangles shows the result of a computation for the combined system (orifice assembly plus valve body plus aerodynamic lens). The results are similar, suggesting that the parts act in a way such that each is nearly independent of the other. Thus, the parts may be modeled separately, reducing the computational complexity.

The location at which losses occur in the orifice-valve assembly can be investigated by analyzing the particle trajectories in the simulations. Representative trajectories are shown in Figure 4 for $600 \mathrm{~nm}$ and $30 \mathrm{~nm}$ particles. Particle losses are predicted to occur in the region immediately down stream of the $100 \mu \mathrm{m}$ critical orifice. In this region there are several changes or steps in the internal diameter of the orifice mounting assembly which appear to be very undesirable. The existence of these steps is a result of using commercially available fittings. In order to improve the particle transmission in the assembly, the orifice and valve assemblies could be redesigned to remove the steps.

\section{Modeling Brownian Motion within the Aerodynamic Lens System}

In our previous studies (Zhang et al. 2002, 2004), we have taken into account the effects of Brownian motion in the flight
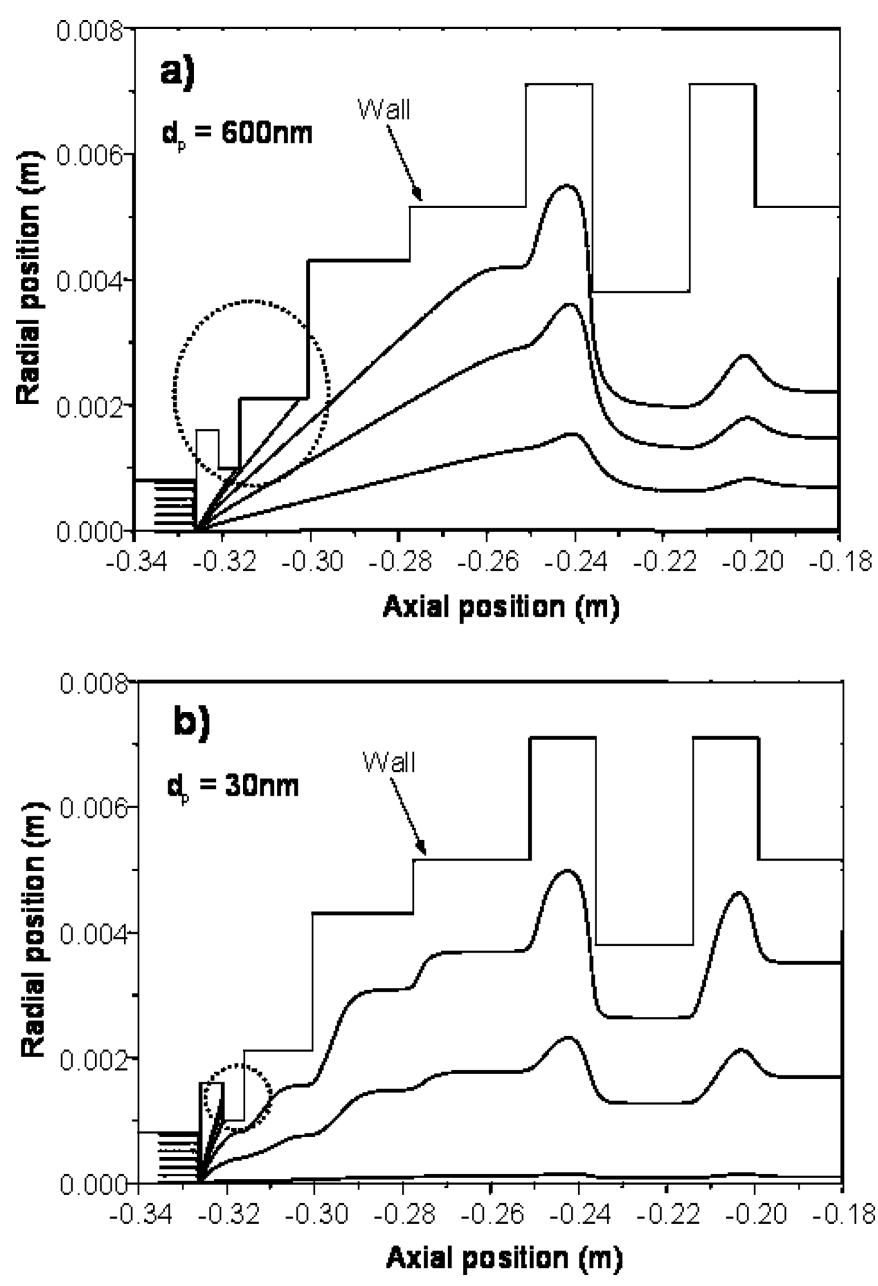

FIG. 4. Particle trajectories and losses encountered in the orifice-valve assembly for two sizes of particles, (a) $600 \mathrm{~nm}$ and (b) $30 \mathrm{~nm}$ diameter. Particles are released from seven positions that are uniformly distributed along the radius at the injection plane. Losses due to impaction are identified by the dotted circle.

chamber on the transmission efficiency, but have not considered Brownian motion within the aerodynamic lens. In this work, we include the beam broadening effects of Brownian motion within the lens system. It is useful to estimate the significance of Brownian diffusion within the lens. The diffusion coefficient resulting from Brownian motion is (Seinfeld and Pandis 1998)

$$
D=\frac{k T C_{c}}{3 \pi \mu d_{p}}
$$

where $k$ is the Boltzmann constant, $T$ is the gas temperature, $C_{c}$ is the Cunningham correction factor, $\mu$ is the gas viscosity, and $d_{p}$ is the geometric particle diameter. For a particle diameter of $100 \mathrm{~nm}$, the average value of $D$ in the lens tube is approximately $3.5 \times 10^{-7} \mathrm{~m}^{2} \mathrm{~s}^{-1}$, and the residence time in the lens $(\tau)$ is about $0.012 \mathrm{~s}$. Thus, the RMS particle displacement due to Brownian 
motion is approximately

$$
s=\sqrt{D \tau}=65 \mu m .
$$

The particle beam that forms at the exit of the lens has a diameter of about $97 \mu \mathrm{m}$, which is comparable to the displacement produced by Brownian motion. Thus, Brownian motion can significantly affect the particle trajectories in the lens and it is therefore important to include its effects in the calculation of the particle transmission efficiency.

As shown in Figure 2, the pressure distribution is not uniform along the flow direction in the lens system. Since Brownian motion is influenced by pressure, we divide the system into two parts as indicated in Figure 1b: the high-pressure zone (lens system), i.e., the region from the critical orifice to the exit of the aerodynamic lens, which is at a pressure ( $p$ ) of $133 \mathrm{~Pa}$ ( 1 torr) or more; and the low-pressure zone (flight region) between the lens exit and the detector, which is at a pressure less than 0.13 $\mathrm{Pa}$ (0.001 torr). This significant difference in pressure requires that Brownian motion be modeled separately in these two zones. For the low pressure zone, we continue to use the procedure of Liu et al. (1995a) as we did in our previous calculations (Zhang et al. 2002, 2004).

For the high-pressure zone, the gas mean free path at $T=300$ $\mathrm{K}$ and $p=1$ torr can be calculated from (Peng et al. 2004)

$$
\lambda=\frac{\sqrt{2 \pi R T} \mu}{2 p}=51 \mu m,
$$

where $R$ is the gas constant. The corresponding Knudsen number,

$$
K n=\lambda / L,
$$

is 0.017 if the diameter of the exit nozzle $(3 \mathrm{~mm})$ is used as the characteristic length $L$. This suggests that the continuum assumption of the Navier-Stokes equations is valid for flow in the high-pressure zone. As a result, the flow parameters calculated from FLUENT by solving the coupled mass, momentum and energy equations are appropriate. However, it should be noted that the particles are considerably smaller than the mean free path, so they respond in a manner characteristic of the free molecular flow regime. With this understanding, the particle tracking method embedded in FLUENT can be used to calculate the particle trajectories by integrating the force balance on the particle (Fluent 2003). This force balance is written in a Lagrangian reference frame, which equates the rate of change of the particle momentum to the forces acting on the particle (in direction $i$ ), i.e.,

$$
\frac{d u_{p, i}}{d t}=F_{D}\left(u_{i}-u_{p, i}\right)+\frac{g_{i}\left(\rho_{p}-\rho\right)}{\rho_{p}}+F_{b i},
$$

where the terms on the right hand side represent drag, gravity and Brownian motion, respectively. Here $u$ and $u_{p}$ are the gas and particle velocities, respectively, $t$ is time, $g$ is the gravitational acceleration, and $\rho$ and $\rho_{p}$ are the gas and particle densities. For submicron particles,

$$
F_{D}=\frac{18 \mu}{\rho_{p} d_{p}^{2} C_{c}},
$$

where $C_{c}$ is calculated from

$$
C_{c}=1+\frac{2 \lambda}{d_{p}}\left[1.257+0.4 \exp \left(-\frac{1.1 d_{p}}{2 \lambda}\right)\right] .
$$

$F_{b i}$ can be calculated from Li and Ahmadi (1992)

$$
F_{b i}=G_{i} \sqrt{\frac{\pi S_{0}}{\Delta t}}
$$

where $G_{i}$ are zero-mean, unit-variance, independent Gaussian random numbers, $\Delta t$ is the time step used in the simulation, and

$$
S_{0}=\frac{216 \mu k T}{\pi^{2} d_{p}^{5} \rho_{p}^{2} C_{c}} .
$$

Note that the time steps $\Delta t$ in this simulation should be small enough such that the drag and other forces are almost constant during $\Delta t$. Within FLUENT, a user-defined function was written to introduce the Brownian force into Equation (5) in order to describe the variation of pressure within the lens system.

Our calculation procedure was to distribute 50 test particles uniformly across the radius of the critical orifice and to track the trajectory of each particle using Equations (5), (8), and (9) to include the effects of Brownian motion within the aerodynamic lens. At the exit of the lens, the subsequent trajectory is determined in part by the radial position of the particle (this determines the ratio of the radial velocity component to the axial velocity component) and is also modified by Brownian motion effects in the flight chamber. Zhang et al. $(2002,2004)$ noted that the radial position and the Brownian motion effects may be treated sequentially. In other words, the first step in the analysis of the low-pressure region was to ignore Brownian motion and determine for each particle whether it impacts the target/vaporizer. To obtain a preliminary estimate of the transmission efficiency, this binary result was then weighted by the fractional flow within the annulus at which the particle was released. This preliminary estimate was in turn multiplied by the result of Liu et al. (1995a) to allow for Brownian diffusion in the low pressure region. This entire numerical experiment was then repeated for a total of five runs for each particle size (i.e., a total of 250 particles at each size) and the results were averaged. The run-to-run variation is indicated by the error bars (standard deviations) on the $7.8 \times 10^{4} \mathrm{~Pa}$ (585 torr) result in Figure 5 


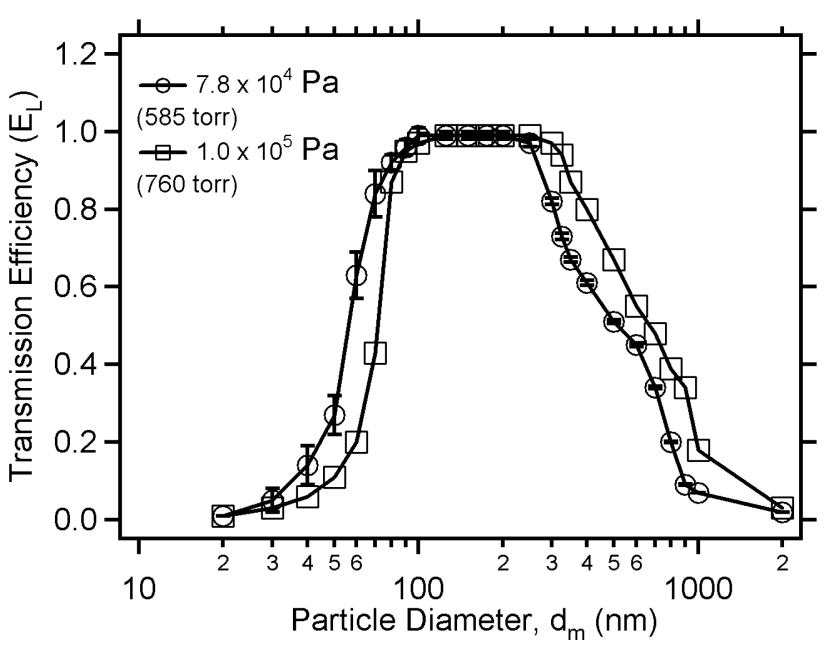

FIG. 5. Calculated transmission efficiency $\left(E_{L}\right)$ at $7.8 \times 10^{4} \mathrm{~Pa}$ (585 torr, line with circles) and at $1.0 \times 10^{5}$ (760 torr, line with squares) with the effects of Brownian motion included. The error bars are standard deviations from 5 model runs. The transmission window is shifted to larger sizes for a larger flow/inlet pressure.

(line with circles). As expected, the variation is greatest for the smallest particles.

A comparison of the curves in Figures 3 and 5 demonstrates the result of including Brownian motion in the calculation. For the $1.0 \times 10^{5} \mathrm{~Pa}$ (760 torr) calculations (line with triangles in Figure 3 and line with squares in Figure 5), the peak in $E_{L}$ between $10 \mathrm{~nm}$ and $30 \mathrm{~nm}$ is removed. These particles no longer impact the vaporizer, but are lost in the lens or vacuum chamber due to broadening of the particle beam. The lower limit of unit transmission efficiency shifts from $75 \mathrm{~nm}$ to $125 \mathrm{~nm}$. As for the relative importance of Brownian motion within the lens and within the low-pressure region, it was found that either would serve to remove the peak between $10 \mathrm{~nm}$ and $30 \mathrm{~nm}$. However, Brownian motion within the lens has more influence on particle sizes $>50 \mathrm{~nm}$ and is largely responsible for the shift in the limit of unit transmission efficiency from $75 \mathrm{~nm}$ to $125 \mathrm{~nm}$.

\section{EXPERIMENTAL DETAILS}

Experimental measurements of the particle transmission efficiency were made on three different AMS instruments located at two different elevations, 2,195 $\mathrm{m}$ (7200 ft) in Laramie, WY (AMS S/N 255-20 owned by the University of Wyoming) and $81 \mathrm{~m} \mathrm{(265} \mathrm{ft)} \mathrm{in} \mathrm{Billerica,} \mathrm{MA} \mathrm{(AMS} \mathrm{S/N} \mathrm{255-8} \mathrm{and} \mathrm{S/N} \mathrm{255-}$ 19 owned by Aerodyne Research, Inc.). The three instruments have nominally identical lens systems, flight paths, and vaporizer geometries. The average ambient pressure is $7.8 \times 10^{4} \mathrm{~Pa}$ (585 torr) in Laramie, Wyoming and $1.0 \times 10^{5} \mathrm{~Pa}$ (760 torr) in Billerica, Massachusetts.

The objective of the measurements is to compare the number and mass loading of a particle population before it enters the AMS with the number and mass loading determined by the AMS as a function of particle size and compare these experimentally determined results with the calculated results presented in Figure 5. This requires that particle size, composition and concentration of the test aerosol be accurately known. For the experimental measurements, an atomizer-classifier system is used to generate nearly monodisperse particles. The size distribution of the classified particles is then measured using a scanning mobility particle sizer (SMPS). A TSI condensation particle counter (CPC 3010) is used to measure the concentration of the test particles. The experimental setup described below was located at the University of Wyoming and was duplicated as closely as possible at Aerodyne Research, Inc.

\section{Aerosol Generation and Delivery}

A TSI monodisperse aerosol generation system (Model $3940 \mathrm{~N}$ ) was used to generate test aerosols of $\mathrm{NH}_{4} \mathrm{NO}_{3}, \mathrm{NaNO}_{3}$, and diethyl hexyl sebacate (DEHS). Solutions of $\mathrm{NH}_{4} \mathrm{NO}_{3}$ and $\mathrm{NaNO}_{3}$ of different strengths were obtained by dissolving the salts in deionized filtered distilled water, while DEHS was dissolved in isopropanol. The solution was atomized and the resulting droplets were dried in a diffusion drier. Silica gel was used for drying water-based droplets and activated carbon was used for isopropanol-based droplets. After passing through the diffusion drier, the particles were charge-equilibrated with an Aerosol Dynamics Inc. (ADI) ${ }^{210}$ Po neutralizer and then passed through a differential mobility analyzer (DMA) with the classifier set at the appropriate voltage to extract the desired particle size. The monodisperse particles were then diluted with filtered dry air and charge-equilibrated with another ADI ${ }^{210}$ Po neutralizer to minimize losses of particles $<100 \mathrm{~nm}$ diameter in the CPC 3010 (Liu and Deshler 2003). The neutralized particles were then routed to a mixing chamber from which point they were distributed to an SMPS, a CPC, and the AMS. A TSI CPC 3010 was used to measure the concentration of the test particles near the entrance to the AMS. A temperature difference of $21^{\circ} \mathrm{C}$ was used between the CPC saturator and condenser instead of the nominal $17^{\circ} \mathrm{C}$ to ensure that smaller particles were activated and counted. To minimize particle loss in the distribution tubing to the CPC and AMS, a single line from the mixing chamber was used for both instruments. This line was divided with a tee approximately $10 \mathrm{~cm}$ in front of the AMS and CPC giving a difference of less than $2 \mathrm{~s}$ in particle residence time between the CPC (flow rate of $16.7 \mathrm{~cm}^{3} \mathrm{~s}^{-1}$ ) and AMS (flow rate of $1.4 \mathrm{~cm}^{3}$ $\left.\mathrm{s}^{-1}\right)$.

The size distribution of the test particles was measured with a TSI SMPS (Model 3936 L10). The performance of the SMPS was verified with reference polystyrene particles (Duke Scientific). A scan rate of 300 seconds was used. For particle mobility diameter, $d_{m}$, less than $250 \mathrm{~nm}$, the fractions of singly and multiply charged particles were determined from the SMPS scan with the sheath air flow set at $6.01 \mathrm{~min}^{-1}$ and aerosol flow at 0.6 $1 \mathrm{~min}^{-1}$ The average volume diameter, $\left\langle d_{v}\right\rangle(\mathrm{nm})$, of the singly charged distribution was obtained from the following relation 
(Raabe 1971)

$$
\left\langle d_{v}\right\rangle=d_{g} \exp \left(1.5 \ln ^{2} \sigma_{g}\right)
$$

where $d_{g}(\mathrm{~nm})$ is the geometric mean diameter and $\sigma_{g}$ is the geometric standard deviation obtained from the SMPS scan of the singly charged particles (Q1). The mass of the particle with average volume diameter multiplied by the total number of particles gives the total mass in the particle distribution for a specific particle density and composition.

For $d_{m}$ larger than $250 \mathrm{~nm}$, the singly charged particle distribution was obtained with the SMPS at lower sheath air flow of $4.01 \mathrm{~min}^{-1}$ and aerosol flow of $0.41 \mathrm{~min}^{-1}$. In cases where the multiply charged particles were larger than the SMPS maximum size range, singly charged fractions were estimated from the charge equilibrium distribution (Wiedensohler 1988) and the parent polydisperse distributions of the atomized dried aerosols obtained previously with the SMPS.

\section{Measurement of $E_{L}\left(d_{v a}\right)$}

Two methods have been used to experimentally determine $E_{L}$ in the AMS with size-selected particles (Jayne et al. 2000). The first is the single particle counting method. When the AMS is operated in particle time-of-flight (PToF) mode, each vaporized particle produces a burst of ions at the monitored $\mathrm{m} / \mathrm{z}$. If the particle is large enough, the ion signal will cross a threshold set just above the background noise and will be counted as an individual particle. The ratio of AMS to CPC counts (particles $\mathrm{cm}^{-3}$ ) gives $E_{L}$ for that size:

$$
E_{L}\left(d_{v a}\right)=\frac{\operatorname{Count}_{A M S}\left(d_{v a}\right)}{\operatorname{Counts}_{C P C}\left(d_{v a}\right)}
$$

where the vacuum aerodynamic diameter $d_{v a}=\rho_{p} / \rho_{0} \times d_{m} \times S$, $\rho_{p}\left(\mathrm{~g} \mathrm{~cm}^{-3}\right)$ is the material density, $\rho_{0}\left(\mathrm{~g} \mathrm{~cm}^{-3}\right)$ is unit density and $\mathrm{S}$ is the empirically determined Jayne shape factor (DeCarlo et al. 2004; Jayne et al. 2000).

For smaller particles $\left(d_{m}<150 \mathrm{~nm}\right)$, the counting method breaks down because some of these particles do not create a sufficiently large ion signal to be cleanly detected above the threshold. However, even though each individual particle may not have enough mass to be counted as a single particle, the total particle mass for the ensemble can still be accurately obtained by signal averaging (Jayne et al. 2000).

The second approach is the mass comparison method

$$
E_{L}\left(d_{v a}\right)=\frac{\operatorname{Mass}_{A M S}\left(d_{v a}\right)}{\operatorname{Mass}_{C P C}\left(d_{v a}\right)}
$$

where $\operatorname{Mass}_{A M S}\left(d_{v a}\right)\left(\mu \mathrm{g} \mathrm{m}^{-3}\right)$ is the mass measured by the AMS and $\operatorname{Mass}_{C P C}\left(d_{v a}\right)\left(\mu \mathrm{g} \mathrm{m}^{-3}\right)$ is calculated from the number of particles counted by the CPC. The SMPS scan is used to determine the $d_{m}$ of the singly charged particles and the relative number of singly, doubly, and triply charged particles passing through the first DMA. The CPC counts the total number of particles entering the AMS and is corrected for doubly and triply charged particles based on the SMPS scan. $\operatorname{Mass}_{C P C}\left(d_{v a}\right)$ is calculated from the number of singly charged particles (Counts CPC $_{C}$, particles $\left.\mathrm{cm}^{-3}\right),\left\langle d_{v}\right\rangle$ (nm, defined in Equation [10]), the material density $\left(\rho_{p}, \mathrm{~g} \mathrm{~cm}^{-3}\right)$ and the Jayne shape factor $(S)$ for the particle composition

$$
\operatorname{Mass}_{C P C}\left(d_{v a}\right)=10^{-9} \operatorname{Counts}_{C P C} \frac{\pi}{6}\left\langle d_{v}\right\rangle^{3} \rho_{p} S
$$

where the factor of $10^{-9}$ accounts for units conversion.

When only singly charged particles are present, $\operatorname{Mass}_{A M S}\left(d_{v a}\right)$ can be determined directly in the MS mode of the AMS by summing over the detected mass at all of the ions for the chemical species. When doubly or triply charged particles pass through the DMA, the PToF mode is used to separate the different size modes in the AMS signal. PToF mode in these experiments monitored only a single fragment $m / z$ and an effective mass to ion ratio (EMI, $\mu \mathrm{g} \mathrm{m}^{-3} \mathrm{~Hz}^{-1}$ ) was used to convert the ion signal to total particle mass. EMIs for each aerosol composition were obtained for a particle size (typically $d_{m} \approx 300 \mathrm{~nm}$ ) where the AMS and CPC count rates matched (i.e., $E_{L}=1$ )

$$
E M I=\frac{\operatorname{Mass}_{C P C}}{A M S_{i}}
$$

where $A M S_{i}\left(\mathrm{~Hz}\right.$ or ions $\left.\mathrm{s}^{-1}\right)$ is the ion signal at the monitored $\mathrm{m} / \mathrm{z}$.

Figure 6 shows an example of the AMS and SMPS data for $d_{m}=278 \mathrm{~nm}$ DEHS particles. The top panel shows the AMS
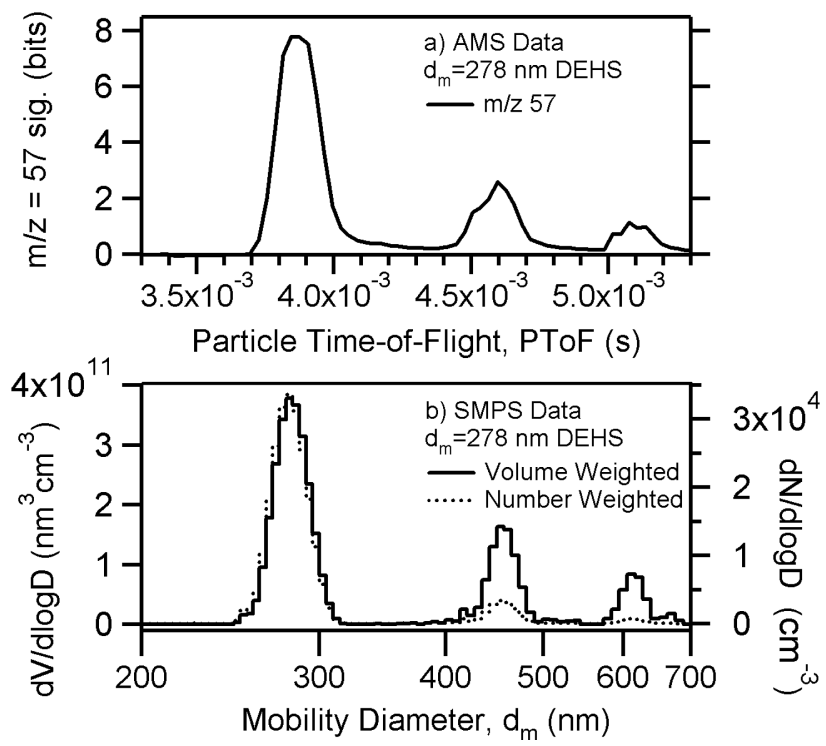

FIG. 6. (a) AMS PToF signal at $m / z=57$ for size-selected $278 \mathrm{~nm}$ DEHS particles. (b) Corresponding SMPS scan weighted by number (dotted line) and weighted by volume (solid line). 
$\mathrm{PToF}$ ion signal for $m / z=57\left(\mathrm{C}_{4} \mathrm{H}_{9}^{+}\right.$ion fragment $)$as a function of particle time-of-flight in the vacuum chamber for a case when the AMS and CPC counts were equal. The bottom panel shows the corresponding SMPS scan weighted by number (dotted line) and weighted by volume (solid line). The EMI calculation uses only the first peak in the AMS signal, corresponding to singly charged particles from the DMA. The CPC particle counts are scaled to the fraction of singly charged particles, based on the SMPS scan. The use of the SMPS system allows the multiply charged particles to be quantitatively accounted for when calculating the particle mass in the Q1 size mode.

Once the EMI is established for the particular aerosol composition, the transmission efficiency can be determined by making simultaneous AMS, CPC, and SMPS measurements of monodisperse particles. For larger particles, $E_{L}\left(d_{v a}\right)$ can be determined using either the count or the mass method. For smaller particles only the mass method is applicable. For the mass method $E_{L}\left(d_{v a}\right)$ is determined from:

$$
E_{L}\left(d_{v a}\right)=\frac{\operatorname{Mass}_{A M S}\left(d_{v a}\right)}{\operatorname{Mass}_{C P C}\left(d_{v a}\right)}=\frac{E M I \times A M S_{i}\left(d_{v a}\right)}{\operatorname{Mass_{CPC}(d_{va})}}
$$

where Mass $_{C P C}$ is defined by Equation (13).

To get detectable average ion count rates for smaller particles, high number concentrations were used $\left(>10^{4} \mathrm{~cm}^{-3}\right)$ as measured by the CPC at the entrance to the AMS. In these cases, coincidence within the CPC reduced the count rate by $13 \%$ for the smallest particles according to a standard analysis (TSI 2000). Even though coincidence rates were small, coincidence was accounted for at all sizes.

All particle concentrations were well above the AMS detection limit. For example, for $\mathrm{NH}_{4} \mathrm{NO}_{3}$ particles with $d_{m}=31 \mathrm{~nm}$, the number of particles used would provide a signal-to-noise ratio (SNR) of $\sim 70$ over 1 minute of averaging. For larger sizes the concentration required for a SNR of 2 falls quickly to $\sim 1 \mathrm{~cm}^{-3}$ and the concentrations used were well above this. This calculation provided a quick check to show that if particles were not detected, it was due to $E_{L}$ rather than the detection sensitivity of the mass spectrometer.

\section{Materials Used}

Several different materials were used for the particles in order to cover a range of densities. $\mathrm{NH}_{4} \mathrm{NO}_{3}$ has a density of $1.72 \mathrm{~g}$ $\mathrm{cm}^{-3}$ for the pure solid and the particles have a Jayne shape factor of $0.8 . \mathrm{NaNO}_{3}$ has a similar Jayne shape factor $(0.85)$ and was investigated because it has a higher material density $(2.26 \mathrm{~g}$ $\left.\mathrm{cm}^{-3}\right)$. Since $d_{v a}$ is a function of density, $d_{v a}$ can be extended to larger sizes for the size range selectable with the DMA. DEHS has a density of $0.91 \mathrm{~g} \mathrm{~cm}^{-3}$ and the liquid particles are spherical $(\mathrm{S}=1)$.

For all three materials, previous experimental work suggests that particle beam broadening and particle bounce at the vaporizer do not decrease the collection efficiency, i.e., $E_{B}\left(d_{v a}\right)=1$

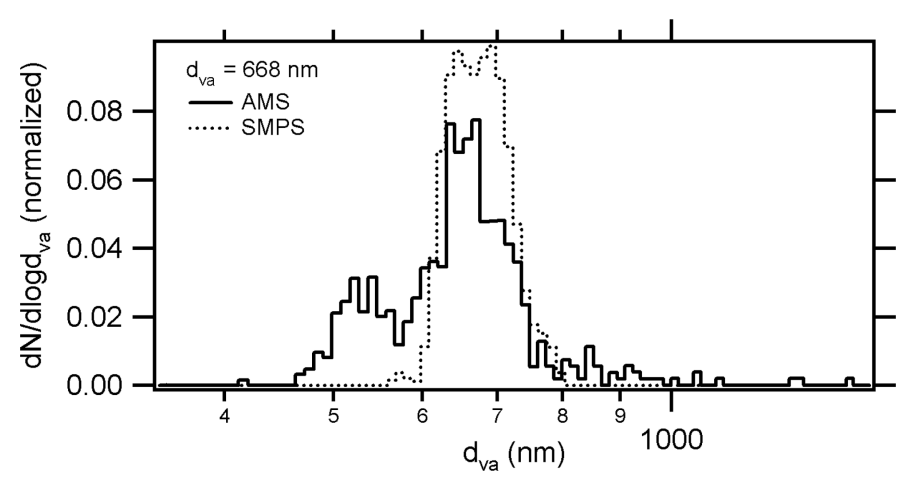

FIG. 7. AMS particle counts and SMPS particle counts for $\mathrm{d}_{v a}=668 \mathrm{~nm}$ $\mathrm{NH}_{4} \mathrm{NO}_{3}$ particles.

and $E_{S}\left(d_{v a}\right)=1$ (Huffman et al. 2005). Thus, the experimentally measured transmission efficiencies are equal to $E_{L}\left(d_{v a}\right)$.

\section{$\mathrm{NH}_{4} \mathrm{NO}_{3}$}

Experiments were performed using $\mathrm{NH}_{4} \mathrm{NO}_{3}$ particles in the mobility diameter range of 31 to $528 \mathrm{~nm}$, corresponding to a $d_{v a}$ range of 43 to $727 \mathrm{~nm}$. For these experiments, the quadrupole mass spectrometer was fixed at $m / z=46$ to measure the $\mathrm{NO}_{2}^{+}$ ion intensity. Although the ion signal at $m / z=30$ is larger than at $m / z=46$ for $\mathrm{NH}_{4} \mathrm{NO}_{3}$, the single particle peaks are sharper at $m / z=46$, allowing better separation of the singly and doubly charged mass distributions. Below $d_{m}$ of $30 \mathrm{~nm}$, the signal was barely discernible even though the mass loading based on the SMPS data was well above the AMS detection limit.

For $d_{m}>300 \mathrm{~nm}$, a shoulder in the signal corresponding to a smaller diameter than the singly charged particle diameter was observed with the AMS as shown with the solid line in Figure 7. No such shoulder was present in the SMPS data (dashed line in Figure 7). (The AMS data in Figure 7 is in particle counts for better comparison with the SMPS data. The shoulder is also present in the AMS mass data.) The reason for this shoulder is not known, but two possible explanations have been proposed. First, some of the particles might fracture during collisions with the walls in the lens system. Second, some of the particles might effloresce in the AMS, effectively changing aerodynamic diameter. The appearance of the shoulder complicates the determination of the $E_{L}$ at sizes $>300 \mathrm{~nm}$ and therefore only the results at smaller particle sizes will be shown. This shoulder is observed only for $\mathrm{NH}_{4} \mathrm{NO}_{3}$ at mobility diameters $>300 \mathrm{~nm}$.

\section{Diethyl hexyl sebacate (DEHS)}

For experiments with DEHS, the quadrupole mass spectrometer was fixed at $m / z=57$, one of the major ion fragments. Initial experiments using a nominal vaporizer temperature of $560^{\circ} \mathrm{C}$ produced distorted AMS size distributions. A reduced vaporizer temperature of $375^{\circ} \mathrm{C}$ produced time-of-flight signals with narrower peaks and with well-separated singly and doubly charged distributions. The distorted results with the higher vaporizer temperature of $560^{\circ} \mathrm{C}$ suggest that larger droplets may 


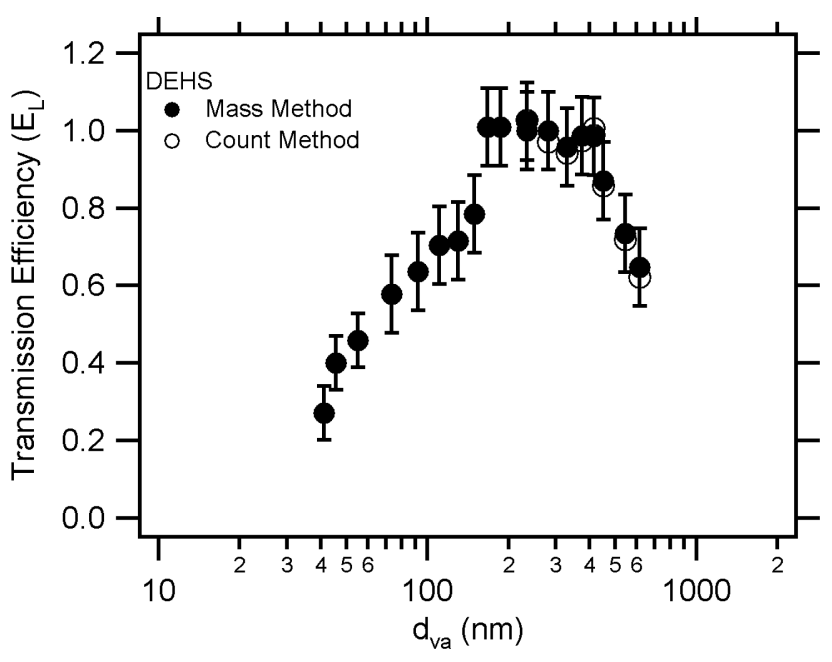

FIG. 8. Experimentally determined $E_{L}$ for DEHS particles at an ambient pressure of $7.8 \times 10^{4} \mathrm{~Pa}$ (585 torr) showing good agreement between the mass method (filled circles) and the count method (open circles).

not be vaporizing completely on contact with the vaporizer. Our hypothesis is that on contact with the vaporizer, the hot vapor formed underneath the remaining droplet forces it off the surface before complete vaporization can occur. These larger droplets appear to leave the vaporizer and later (on a ms timescale) vaporize on a nearby surface. Reducing the temperature seems to evenly vaporize the droplets and eliminate this effect, thus producing distinct singly and multiply charged distributions. Thermal degradation of the DEHS at the higher vaporizer temperature could also contribute to the broadened time-of-flight traces.

For DEHS, both the direct counting method and mass method could be used for particles $>240 \mathrm{~nm}$. The DEHS $E_{L}$ results for $d_{v a}$ ranging from 41 to $614 \mathrm{~nm}$ are shown in Figure 8 (open circles for the count method and filled circles for the mass method). The error bars shown on the solid circles are estimated from the variance between different sets of data and on the estimated error of $\pm 15 \%$ in $E M I$. The error bars are \pm 0.1 for values of $E_{L}>0.5$ and \pm 0.07 for values of $E_{L}<0.5$, and are shown only for the solid points in order to simplify the figure. The single particle counting method and the mass method agree quite well.

\section{$\mathrm{NaNO}_{3}$}

To extend the measurements to larger $d_{v a}, \mathrm{NaNO}_{3}$ particles were investigated. For these experiments, the quadrupole mass spectrometer was fixed at $m / z=30$ to measure $\mathrm{NO}^{+}$ion intensity. The optimum vaporizer temperature for investigating $\mathrm{NaNO}_{3}$ was about $800^{\circ} \mathrm{C}$. The higher temperature used reflects the lower volatility of this species compared to DEHS or $\mathrm{NH}_{4} \mathrm{NO}_{3}$. This temperature was arrived at by selecting the narrowest time-of-flight trace for the singly charged particles as a function of vaporizer temperature. For this $E_{L}$ experiment we focus on larger $d_{v a}$ ranging from 296 to $777 \mathrm{~nm}$.

\section{RESULTS AND DISCUSSION}

\section{Transmission Efficiency at Different Ambient Pressures}

Since many of the AMS systems are operated at slightly different ambient pressures, we wanted to investigate this effect on the transmission properties of the lens system. The FLUENT calculations were performed at two different pressures, $7.8 \times 10^{4}$ $\mathrm{Pa}$ (585 torr) and $1.0 \times 10^{5} \mathrm{~Pa}$ (760 torr) to match the ambient pressures for the two sets of laboratory data. Figure 5 displays the calculated transmission efficiencies including the effects of Brownian motion. The values of $d_{p}$ and $E_{L}$ for the curves in Figure 5 are listed in Table 2. Figure 5 shows that lower pressure favors transmission of smaller particles and higher pressure favors transmission of larger particles. The overall shape of the transmission window remains relatively constant and is effectively moved to smaller or larger sizes as the ambient pressure is changed.

Figure 9 shows the experimental $E_{L}$ results and the FLUENT modeling result at $7.8 \times 10^{4} \mathrm{~Pa}$ (585 torr). The error bars on the experimental points are \pm 0.1 for values of $E_{L}>0.5$ and

TABLE 2

Particle diameters and calculated transmission efficiencies at $1.0 \times 10^{5} \mathrm{~Pa}$ (760 torr) and $7.8 \times 10^{4} \mathrm{~Pa}$ (585 torr)

\begin{tabular}{lcc}
\hline & $\begin{array}{c}1.0 \times 10^{5} \mathrm{~Pa} \\
(760 \text { torr })\end{array}$ & $\begin{array}{c}7.8 \times 10^{4} \mathrm{~Pa} \\
(585 \text { torr }) \\
d_{p} \\
E_{L}\end{array}$ \\
\hline 20 & $0.01 \pm 0.01$ & $0.01 \pm 0.01$ \\
30 & $0.03 \pm 0.03$ & $0.05 \pm 0.03$ \\
40 & $0.06 \pm 0.04$ & $0.14 \pm 0.05$ \\
50 & $0.11 \pm 0.05$ & $0.27 \pm 0.05$ \\
60 & $0.20 \pm 0.05$ & $0.63 \pm 0.06$ \\
70 & $0.43 \pm 0.06$ & $0.84 \pm 0.06$ \\
80 & $0.87 \pm 0.06$ & $0.92 \pm 0.02$ \\
90 & $0.95 \pm 0.02$ & $0.96 \pm 0.02$ \\
100 & $0.97 \pm 0.02$ & $0.99 \pm 0.02$ \\
125 & $0.99 \pm 0.02$ & $0.99 \pm 0.01$ \\
150 & $0.99 \pm 0.01$ & $0.99 \pm 0.01$ \\
175 & $0.99 \pm 0.01$ & $0.99 \pm 0.01$ \\
200 & $0.99 \pm 0.01$ & $0.99 \pm 0.01$ \\
250 & $0.99 \pm 0.01$ & $0.97 \pm 0.01$ \\
300 & $0.97 \pm 0.01$ & $0.82 \pm 0.00$ \\
325 & $0.94 \pm 0.01$ & $0.73 \pm 0.01$ \\
350 & $0.87 \pm 0.01$ & $0.67 \pm 0.01$ \\
400 & $0.80 \pm 0.01$ & $0.61 \pm 0.01$ \\
500 & $0.67 \pm 0.01$ & $0.51 \pm 0.01$ \\
600 & $0.55 \pm 0.01$ & $0.45 \pm 0.01$ \\
700 & $0.48 \pm 0.01$ & $0.34 \pm 0.01$ \\
800 & $0.39 \pm 0.01$ & $0.20 \pm 0.01$ \\
900 & $0.34 \pm 0.01$ & $0.09 \pm 0.01$ \\
1000 & $0.18 \pm 0.01$ & $0.07 \pm 0.01$ \\
2000 & $0.03 \pm 0.01$ & $0.02 \pm 0.01$ \\
\hline & &
\end{tabular}




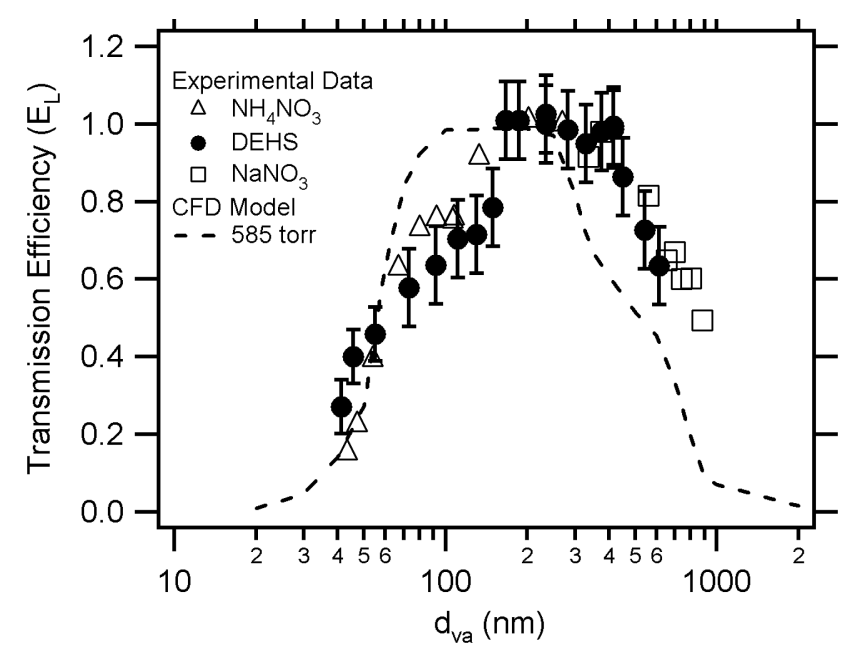

FIG. 9. Experimental $E_{L}$ for $\mathrm{NH}_{4} \mathrm{NO}_{3}$ (triangles), DEHS (solid circles), and $\mathrm{NaNO}_{3}$ (squares) at an ambient pressure of $7.8 \times 10^{4} \mathrm{~Pa}$ (585 torr). The dashed line is the CFD model result for $7.8 \times 10^{4}(585)$ torr and is re-plotted from Figure 5.

\pm 0.07 for values of $E_{L}<0.5$, and are estimated from the variance between different sets of data and on the estimated error of $\pm 15 \%$ in EMI. Error bars are shown only for the solid points in order to simplify the figure. The measurements with the three different types of particles are consistent with each other and produce a pattern similar in shape if not in position to the model result. On the small size end, the model overestimates $E_{L}$ below $\sim 150 \mathrm{~nm}$ by 20 to $40 \%$. On the large size end, the measured $E_{L}$ is larger than predicted for sizes beyond $\sim 350 \mathrm{~nm}$. The $E_{L}$ does not begin to drop until about $415 \mathrm{~nm}$ as compared to the model result which drops off at about $250 \mathrm{~nm}$. The better-thanpredicted $E_{L}$ at the large size end might be due to the fact that in the calculation a boundary condition is imposed such that if a particle collides with the wall (see Figure 4) it is removed from the calculation. In the real system, if a particle collides with the wall it could rebound, become re-entrained in the flow and ultimately reach the vaporizer. This explanation seems plausible for the solid particles, but implausible for the liquid DEHS particles.

An interesting result is the higher $E_{L}$ observed for $\mathrm{NH}_{4} \mathrm{NO}_{3}$ between 60 and $130 \mathrm{~nm}$ compared to DEHS. DEHS droplets are spherical and would be expected to focus better than the nonspherical $\mathrm{NH}_{4} \mathrm{NO}_{3}$ particles and should therefore have a better $E_{L}$. This discrepancy could be due to an error in determining the $E M I$ for $\mathrm{NH}_{4} \mathrm{NO}_{3}$. For example, if the larger $\mathrm{NH}_{4} \mathrm{NO}_{3}$ particles used for the $E M I$ are not completely dry, this would lead to an overestimate of $E M I$ and a corresponding overestimate of $E_{L}$ for $\mathrm{NH}_{4} \mathrm{NO}_{3}$.

Figure 10 shows the experimental results obtained on two different AMS instruments and the model calculation at $1.0 \times$ $10^{5} \mathrm{~Pa}$ (760 torr). For $\mathrm{NH}_{4} \mathrm{NO}_{3}$ and $\mathrm{NaNO}_{3}$, and for each instrument, two sets of data taken at different times were averaged together to obtain the points shown in the figure. Only one set of data was collected for DEHS. The error bars are estimated from

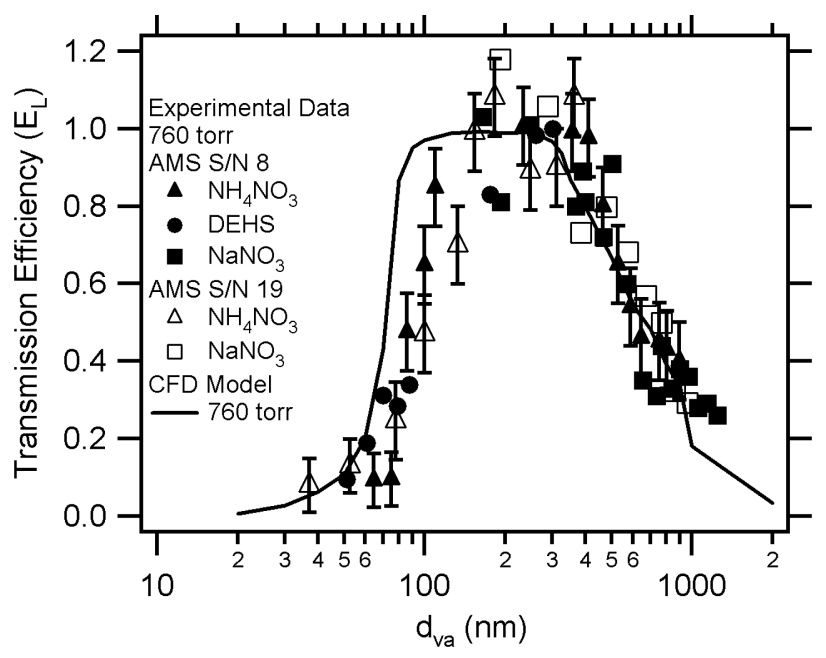

FIG. 10. Experimental $E_{L}$ for $\mathrm{NH}_{4} \mathrm{NO}_{3}$ (triangles), DEHS (circles), and $\mathrm{NaNO}_{3}$ (squares) at an ambient pressure of $1.0 \times 10^{5}$ (760 torr) with two different AMS instruments, S/N 8 (filled symbols) and S/N 19 (open symbols). The solid line is the CFD model result for $1.0 \times 10^{5}$ (760 torr) and is re-plotted from Figure 5.

the variance within and between the different sets of data and from the estimated error of $\pm 15 \%$ in $E M I$. The error bars are \pm 0.1 for values of $E_{L}>0.5$ and \pm 0.07 for values of $E_{L}<0.5$, and are shown only for the $\mathrm{NH}_{4} \mathrm{NO}_{3}$ points in order to simplify the figure. The results for the three different materials agree well within the error bars.

As with the $7.8 \times 10^{4} \mathrm{~Pa}$ (585 torr) results, the experimental measurements at $1.0 \times 10^{5} \mathrm{~Pa}$ (760 torr) are smaller than the model prediction for smaller particle sizes $\left(d_{v a}<150 \mathrm{~nm}\right)$. In contrast to the $7.8 \times 10^{4} \mathrm{~Pa}$ (585 torr) results, there is very good agreement between the measurements and the model from 150 $\mathrm{nm}$ to $800 \mathrm{~nm}$. It is not understood why these results should agree rather well with the model whereas the results at $7.8 \times$ $10^{4} \mathrm{~Pa}$ (585 torr) agree significantly less well.

Figure 11 shows a comparison of the two sets of experimental data and the two model calculations at the two operating pressures. The experimental data have been averaged over all three materials within equally spaced bins on the $\log \left(d_{v a}\right)$ axis. The averaged experimental points are given in Table 3. The error bars in Table 3 are estimated from the error bars on each set of data and the variance between the sets of data for different materials and instruments. The experimental results agree well at the two pressures for particles with $d_{v a}>250 \mathrm{~nm}$, even though the model calculations suggest that the transmission efficiency should be larger in this size range for the higher ambient pressure.

\section{Effect of Aperture Diameters}

The AMS aerodynamic lens is custom machined and there are small variations from one assembly to the next because of machining tolerances. The good agreement between results for two different AMS instruments (Figure 10) suggests that these 


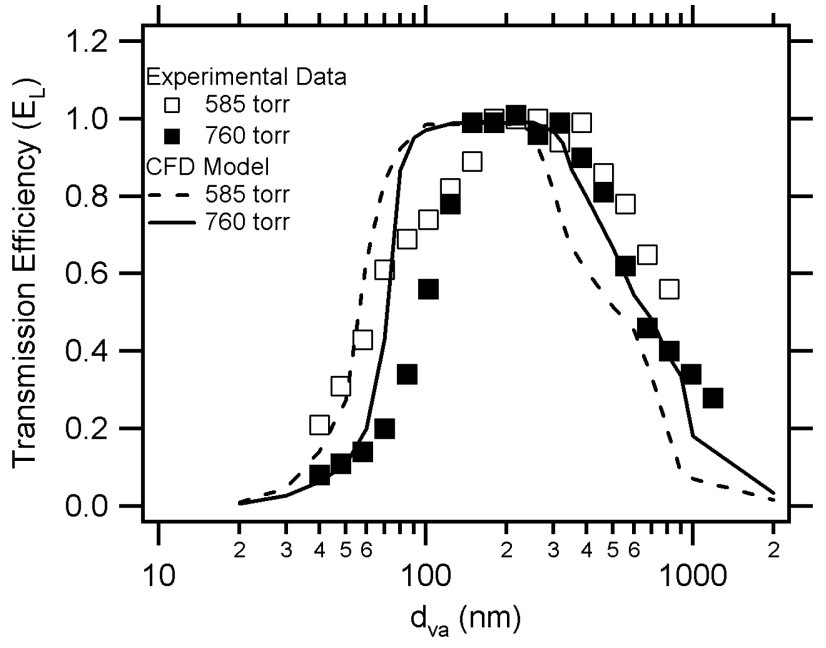

FIG. 11. Comparison of averaged experimental $E_{L}$ at two ambient pressures of $1.0 \times 10^{5}$ (760 torr) and $7.8 \times 10^{4} \mathrm{~Pa}$ (585 torr) with the CFD model results at the two pressures (re-plotted from Figure 5). The calculated and experimental values are given in Tables 2 and 3.

machining variations do not impact the overall transmission efficiency of the AMS. We also investigated this issue with numerical calculations to study the sensitivity of the overall transmission efficiency to small changes in lens aperture dimensions. Table 1 lists the specified and the actual (measured) dimensions

TABLE 3

Particle diameters and averaged experimental transmission efficiencies at $1.0 \times 10^{5} \mathrm{~Pa}(760$ torr $)$ and $7.8 \times 10^{4} \mathrm{~Pa}$

(585 torr)

\begin{tabular}{lcc}
\hline & $\begin{array}{c}1.0 \times 10^{5} \mathrm{~Pa} \\
(760 \text { torr })\end{array}$ & $\begin{array}{c}7.8 \times 10^{4} \mathrm{~Pa} \\
(585 \text { torr }) \\
d_{v a}\end{array}$ \\
\hline$E_{L}$ & $E_{L}$ \\
\hline 40 & $0.08 \pm 0.07$ & $0.21 \pm 0.07$ \\
58 & $0.11 \pm 0.07$ & $0.31 \pm 0.07$ \\
70 & $0.14 \pm 0.07$ & $0.43 \pm 0.07$ \\
85 & $0.20 \pm 0.07$ & $0.61 \pm 0.1$ \\
102 & $0.34 \pm 0.07$ & $0.69 \pm 0.1$ \\
123 & $0.56 \pm 0.1$ & $0.74 \pm 0.1$ \\
149 & $0.78 \pm 0.1$ & $0.82 \pm 0.1$ \\
180 & $0.99 \pm 0.1$ & $0.89 \pm 0.1$ \\
217 & $0.99 \pm 0.1$ & $1.0 \pm 0.1$ \\
262 & $1.0 \pm 0.1$ & $1.0 \pm 0.1$ \\
316 & $0.96 \pm 0.1$ & $1.0 \pm 0.1$ \\
382 & $0.99 \pm 0.1$ & $0.94 \pm 0.1$ \\
461 & $0.9 \pm 0.1$ & $0.99 \pm 0.1$ \\
557 & $0.81 \pm 0.1$ & $0.86 \pm 0.1$ \\
672 & $0.62 \pm 0.1$ & $0.78 \pm 0.1$ \\
812 & $0.46 \pm 0.07$ & $0.65 \pm 0.1$ \\
980 & $0.4 \pm 0.07$ & $0.56 \pm 0.1$ \\
1183 & $0.34 \pm 0.07$ & \\
\hline
\end{tabular}

of the aerodynamic lens apertures in the University of Wyoming AMS. Transmission efficiency calculations (without Brownian motion) using these two sets of dimensions showed small differences for the smallest size particles $(<50 \mathrm{~nm})$. A slight increase in transmission efficiency for the actual dimensions around $30 \mathrm{~nm}$ may be due to the change in size of the last lens aperture (or nozzle) because the Zhang et al. (2004) calculations indicate that this aperture controls transmission in this size range. However, once Brownian motion is included, the transmission efficiency is the same for both sets of dimensions. In this study, we did not systematically investigate the role of each aperture in the lens. We also did not study the effect on the transmission efficiency if the apertures are not centered on the lens axis.

\section{Effect of Critical Orifice Mounting Assembly Geometry}

Figure 4 shows calculated particle trajectories that impact the walls of the lens system, particularly just downstream of the critical orifice. Particle loss by impaction was investigated numerically and experimentally by modifying the fitting that holds the critical orifice to remove some of the steps. Figure 12a shows
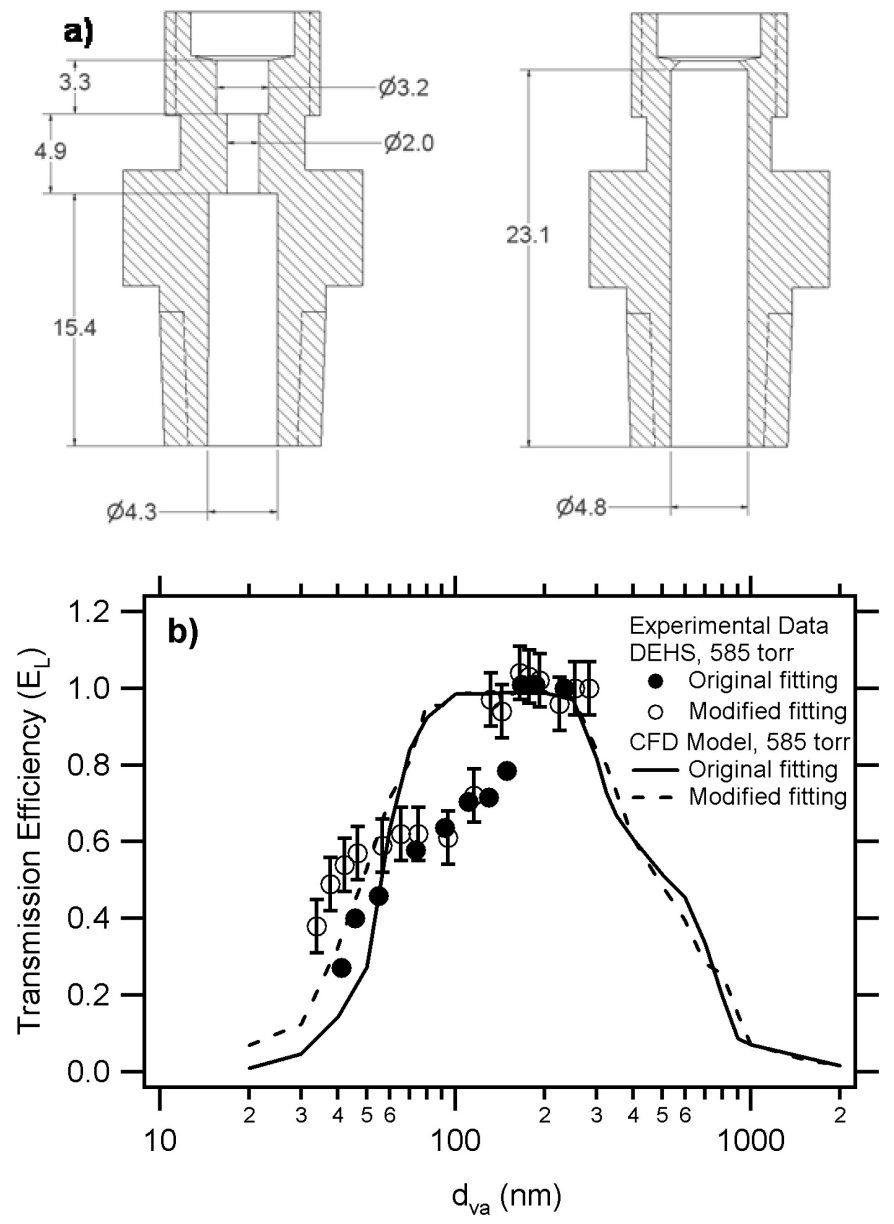

FIG. 12. (a) Schematic of the original and modified orifice fitting (all dimensions in $\mathrm{mm}$ ). (b) Experimentally measured transmission efficiency $\left(E_{L}\right)$ for the original (solid circles) and modified (open circles) fittings, and calculated $E_{L}$ for the original (solid line) and modified (dashed line) fittings. 
schematics of the original and modified fitting. Figure $12 \mathrm{~b}$ shows the corresponding calculated and measured transmission efficiencies. The calculated transmission efficiency (dashed line) is improved for small particles $(<60 \mathrm{~nm})$ and remains unchanged for larger particles $(>150 \mathrm{~nm})$. Model calculations on the individual components of the lens system showed that the modifications to the orifice fitting significantly improved the transmission of small particles through the orifice plus valve assembly so that the cutoff on the small particle side is now controlled by the lens. On the large particle side ( $>400 \mathrm{~nm}$ ), modification of the orifice fitting removed the first impact point indicated in Figure 4a, but not the second. Thus, the transmission efficiency for larger particles is still controlled by the orifice plus valve assembly. The experimental results for the modified fitting (open circles) also show an increase in the transmission efficiency for particles $<60 \mathrm{~nm}$, in qualitative agreement with the calculations.

\section{Comparison with Other Experimental Measurements of Transmission Efficiency}

Several experimental evaluations of a closely related aerodynamic lens designed by Liu et al. (1995a) have been published previously (Jayne et al. 2000; Liu et al. 1995b; Tobias et al. 2000). The main differences between the Liu et al. (1995a) lens and the lens described in this paper are the overall length $(\sim 290 \mathrm{~mm}$ vs. $177.8 \mathrm{~mm}$ ), the shape of the nozzle (or final aperture), and the fact that some of the middle apertures are $10 \mathrm{~mm}$ long channels rather than thin plates. The Jayne et al. (2000) lens evaluation was performed in an AMS, while Liu et al. (1995b) and Tobias et al. (2000) used other vacuum chamber designs and detection schemes. The results in Liu et al. (1995b) and Tobias et al. (2000) show much better transmission efficiency for particles with $d_{m}<50 \mathrm{~nm}$ than these results. However, the Liu et al. (1995b) and Tobias et al. (2000) results are not directly comparable to these results because of the much larger collection angle at the detector (47 mrad in Liu et al. (1995b) vs. $8 \mathrm{mrad}$ for the AMS). The larger collection angle means that small particles will still impact the detector even with significant Brownian motion broadening of the particle beam.

Liu et al. (1995b) and Tobias et al. (2000) did not measure transmission efficiencies for particles larger than $250 \mathrm{~nm}$ and $500 \mathrm{~nm}$, respectively. Jayne et al. (2000) measured somewhat better transmission efficiency for particles with $d_{v a}>350 \mathrm{~nm}$ than these results for the same collection angle, but did not make measurements for particles with $d_{v a}<100 \mathrm{~nm}$. We performed FLUENT calculations on the lens used in Jayne et al. (2000) and the results suggested that the transmission efficiency should be the same as for the current lens. It is not clear why Jayne et al. (2000) measured better transmission efficiency for $d_{v a}>350$ $\mathrm{nm}$, but it may be related to changes in the configuration of the aperture between vacuum chambers just after the lens exit in the AMS. This aperture was changed from a skimmer cone to a constant diameter channel between Jayne et al. (2000) and this article.

\section{CONCLUSIONS}

We have performed new CFD model calculations and made an extensive set of experimental measurements for the transmission efficiency of the Aerodyne AMS aerodynamic lens system. One important result of the CFD model calculations is the realization that the critical orifice fitting and the valve assembly have a large impact on $E_{L}$ at particles sizes $<70 \mathrm{~nm}$ and $>350 \mathrm{~nm}$ and that these structures need to be explicitly included in the model. In addition, the model now treats the effect of Brownian motion within the lens system.

Experimental measurements used three different types of particles and covered a $d_{v a}$ range of 35 to $1200 \mathrm{~nm}$. Experiments and calculations were performed at two different ambient pressures. At $7.8 \times 10^{4} \mathrm{~Pa}$ (585 torr), the $E_{L}$ obtained experimentally agrees with the numerical calculations in the $d_{v a}$ range of 160 to $250 \mathrm{~nm}$. Below $d_{v a}=160 \mathrm{~nm}$, the $E_{L}$ obtained experimentally is less than predicted by 20 to $40 \%$. Above $250 \mathrm{~nm}$, the experimental $E_{L}$ is greater than the numerical prediction. At $1.0 \times 10^{5} \mathrm{~Pa}$ (760 torr), the measured $E_{L}$ is less than predicted for $d_{v a}<150$ $\mathrm{nm}$ and agrees well with predicted values for $d_{v a}>150 \mathrm{~nm}$. The deviations between measured and calculated $E_{L}$ for $d_{v a}<150$ $\mathrm{nm}$ are as yet unexplained.

The implications of these results for AMS measurements of ambient atmospheric aerosol particles are small in most cases. For typical accumulation mode particles ( $\sim 50$ to $1,000 \mathrm{~nm}$ diameter), the $E_{L}$ is close to $100 \%$ and the AMS quantitatively measures mass loadings. This conclusion is supported by numerous field campaigns in which the correlation between AMS data and other collocated instrumentation is within $\pm 25 \%$, even over long time periods and over a variety of chemical compositions (Canagaratna et al. 2007; Drewnick et al. 2004; Takegawa et al. 2005; Zhang et al. 2005). This correlation might be improved slightly by including a size dependent $E_{L}$. In contrast, in cases where nucleation mode particles are present, for example during a nucleation event in Pittsburg, Pennsylvania in 2002 (DeCarlo et al. 2007) and in the Gulf of Maine in 2004 (Quinn et al. 2006), the size dependent $E_{L}$ is crucial for determining the quantitative mass loading.

\section{REFERENCES}

Allan, J. D., Bower, K. N., Coe, H., Boudries, H., Jayne, J. T., Canagaratna, M. R., Millet, D. B., Goldstein, A. H., Quinn, P. K., Weber, R. J., and Worsnop, D. R. (2004). Submicron Aerosol Composition at Trinidad Head, CA during ITCT 2K2, Its Relationship with Gas Phase Volatile Organic Carbon and Assessment of Instrument Performance, J Geophys. Res. 109:D23S24, doi:10.1029/2003JD004208.

Allan, J. D., Coe, H., N. Bower, K., Williams, P. I., Gallagher, M. W., Alfarra, M. R., Jiménez, J. L., Worsnop, D. R., Jayne, J. T., Canagaratna, M. R., Nemitz, E., and McDonald, A. G. (2003a). Quantitative Sampling Using an Aerodyne Aerosol Mass Spectrometer 1. Techniques of Data Interpretation and Error Analysis, J. Geophys. Res. 108(D3):4090 doi:4010.1029/2002JD002358.

Allan, J. D., Jiménez, J. L., Coe, H., Bower, K. N., Williams, P. I., Gallagher, M. W., and Worsnop, D. R. (2003b). Quantitative Sampling Using an Aerodyne Aerosol Mass Spectrometer 2. Measurements of Fine Particulate Chemical Composition in Two UK Cities, J. Geophys. Res. 108(D3):4091 doi:4010.1029/2002JD002359. 
Canagaratna, M. R., Jayne, J. T., Jiménez, J. L., Allan, J. D., Alfarra, M. R., Zhang, Q., Onasch, T. B., Drewnick, F., Coe, H., Middlebrook, A., Delia, A., Williams, L. R., Trimborn, A. M., Northway, M. J., DeCarlo, P. F., Kolb, C. E., Davidovits, P., and Worsnop, D. R. (2007). Chemical and Microphysical Characterization of Ambient Aerosols with the Aerodyne Aerosol Mass Spectrometer, Mass Spectrometry Reviews 26:185-222.

DeCarlo, P., Slowik, J. G., Worsnop, D. R., Davidovits, P., and Jiménez, J. L. (2004). Particle Morphology and Density Characterization by Combined Mobility and Aerodynamic Diameter Measurements. Part 1: Theory, Aerosol Sci. Technol. 38:1185-1205, doi: 1110.1080/027868290903907.

DeCarlo, P., Zhang, Q., Worsnop, D. R., and Jiménez, J. L. (2007). Synthesizing SMPS and AMS Measurements into a Consistent Representation of the Aerosol Population: Technique Description and Application to Field Data: in preparation.

Drewnick, F., Schwab, J. J., Hogrefe, O., Peters, S., Husain, L., Diamond, D., Weber, R., and Demerjian, K. L. (2003). Intercomparison and Evaluation of Four Semi-continuous PM-2.5 Sulfate Instruments, Atmos. Environ. 37:33353350.

Drewnick, F., Schwab, J. J., Jayne, J. T., Canagaratna, M., Worsnop, D. R., and Demerjian, K. L. (2004). Measurement of Ambient Aerosol Composition during the PMTACS-NY 2001 using an Aerosol Mass Spectrometer. Part I: Mass Concentrations, Aerosol Sci. Technol. 38(S1):92103.

Fluent. (2003). Fluent User's Guide, Fluent Inc., Lebanon, NH.

Gard, E., Mayer, J. E., Morrical, B. D., Dienes, T., Fergenson, D. P., and Prather, K. A. (1997). Real-Time Analysis of Individual Atmospheric Aerosol Particles: Design and Performance of a Portable ATOFMS, Anal. Chem. 69:40834091.

Huffman, J. A., Jayne, J. T., Drewnick, F., Aiken, A. C., Onasch, T., Worsnop, D. R., and Jiménez, J. L. (2005). Design, Modeling, Optimization, and Experimental Tests of a Particle Beam Width Probe for the Aerodyne Aerosol Mass Spectrometer, Aerosol Sci. Technol. 39(12):1143-1163.

Jayne, J. T., Leard, D. C., Zhang, X., Davidovits, P., Smith, K. A., Kolb, C. E., and Worsnop, D. R. (2000). Development of an Aerosol Mass Spectrometer for Size and Composition Analysis of Submicron Particles, Aerosol Sci. Technol. 33:49-70.

Jiménez, J. L., Jayne, J. T., Shi, Q., Kolb, C. E., Worsnop, D. R., Yourshaw, I., Seinfeld, J. H., Flagan, R. C., Zhang, X., Smith, K. A., Morris, J., and Davidovits, P. (2003). Ambient Aerosol Sampling Using the Aerodyne Aerosol Mass Spectrometer, J. Geophys Res. 108(D7):8425 doi:8410.1029/2001JD001213.

Li, A., and Ahmadi, G. (1992). Dispersion and Deposition of Spherical Particles from Point Sources in a Turbulent Channel Flow, Aerosol Sci. Technol. 16(4):209-226.

Liu, P., Ziemann, P. J., Kittleson, D. B., and McMurry, P. H. (1995a). Generating Particle Beams of Controlled Dimensions and Divergence: I. Theory of Particle Motion in Aerodynamic Lenses and Nozzle Expansions, Aerosol Sci. Technol. 22:293-313.

Liu, P., Ziemann, P. J., Kittleson, D. B., and McMurry, P. H. (1995b). Generating Particle Beams of Controlled Dimensions and Divergence: II. Experimental Evaluation of Particle Motion in Aerodynamic Lenses and Nozzle Expansions, Aerosol Sci. Technol. 22:314-324.

Liu, P. S. K., and Deshler, T. (2003). Causes of Concentration Differences between a Scanning Mobility Particle Sizer and a Condensation Particle Counter, Aerosol Sci. Technol. 37:916-923.

McMurry, P. (2000). A Review of Atmospheric Aerosol Measurements, Atmos. Environ. 34:1959-1999.
Murphy, D. M., and Thomson, D. S. (1997). Chemical Composition of Single Aerosol Particles at Idaho Hill: Positive Ion Measurements, J. Geophys. Res. 102: 6341-6352; 6353-6368.

Peng, Y., Lu, X., and Luo, J. (2004). Nanoscale Effect on Ultrathin Gas Film Lubrication in Hard Disk Drive, J. Tribol. 126:347-352.

Quinn, P. K., Bates, T. S., Coffman, D., Onasch, T. B., Worsnop, D., Baynard, T., de Gouw, J. A., Goldan, P. D., Kuster, W. C., Williams, E., Roberts, J. M., Lerner, B., Stohl, A., Pettersson, A., and Lovejoy, E. R. (2006). Impacts of Sources and Aging on Submicrometer Aerosol Properties in the Marine Boundary Layer Across the Gulf of Maine, J. Geophys. Res. 111, D23S36: doi:10.1029/2006JD007582.

Raabe, O. G. (1971). Particle Size Analysis Utilizing Grouped Data and the Log-Normal Distribution, J. Aerosol Sci. 2:289-303.

Schreiner, J., Schild, U., Voigt, C., and Mauersberger, K. (1999). Focusing of Aerosols into a Particle Beam at Pressures from 10 to 150 Torr, Aerosol Sci. Technol. 31:373-382.

Seinfeld, J. H., and Pandis, S. N. (1998). Atmospheric Chemistry and Physics: From Air Pollution to Climate Change. John Wiley and Sons, Inc., New York.

Su, Y., Sipin, M. F., Furutani, H., and Prather, K. A. (2004). Development and Characterization of an Aerosol Time-of-Flight Mass Spectrometer with Increased Detection Efficiency, Anal. Chem. 76:712-719.

Takegawa, N., Miyazaki, Y., Kondo, Y., Komazaki, Y., Miyakawa, T., Jiménez, J. L., Jayne, J. T., Worsnop, D. R., Allan, J., and Weber, R. J. (2005). Characterization of an Aerodyne Aerosol Mass Spectrometer (AMS): Intercomparison with other aerosol instruments, Aerosol Sci. Technol. 39:760-770.

Tobias, H. J., Kooiman, P. M., Docherty, K. S., and Ziemann, P. J. (2000). RealTime Chemical Analysis of Organic Aerosols Using a Thermal Desorption Particle Beam Mass Spectrometer, Aerosol Sci. Technol. 33:170-190.

TSI, 2000. Model 3010 Condensation Particle Counter Instruction Manual, Rev. E, TSI, Minnesota.

Wang, X., Gidwani, A., Girshick, S. L., and McMurry, P. H. (2005a). Aerodynamic Focusing of Nanoparticles: II. Numerical Simulation of Particle Trajectories through Aerodynamic Lenses, Aerosol Sci. Technol. 39:624-636.

Wang, X., Kruis, F. E., and McMurry, P. H. (2005b). Aerodynamic Focusing of Nanoparticles: I. Guidelines for Designing Aerodynamic Lenses for Nanoparticles, Aerosol Sci. Technol. 39:611-623.

Wiedensohler, A. (1988). An Approximation of the Bipolar Charge Distribution for Particles in the Submicron Size Range, J. Aerosol Sci. 19(3):387-389.

Zelenyuk, A., and Imre, D. (2005). Single Particle Laser Ablation Time-ofFlight Mass Spectrometer: An Introduction to SPLAT, Aerosol Sci. Technol. 39(6):554-568

Zhang, Q., Canagaratna, M. R., Jayne, J. T., Worsnop, D. R., and Jiménez, J. L. (2005). Time and Size-Resolved Chemical Composition of Submicron Particles in Pittsburgh-Implications for Aerosol Sources and Processes, $J$. Geophys. Res. 110:D07S09, doi:10.1029/2004JD004649.

Zhang, X., Smith, K. A., Worsnop, D. R., Jiménez, J., Jayne, J. T., and Kolb, C. E. (2002). A Numerical Characterization of Particle Beam Collimation by an Aerodynamic Lens-Nozzle System. Part 1, An Individual Lens or Nozzle, Aerosol Sci. Technol. 36(5):617-631.

Zhang, X., Smith, K. A., Worsnop, D. R., Jiménez, J. L., Jayne, J. T., Kolb, C. E., Morris, J., and Davidovits, P. (2004). Numerical Characterization of Particle Beam Collimation: Part II Integrated Aerodynamic Lens-Nozzle System, Aerosol Sci. Technol. 38(6):619-638.

Ziemann, P. J., Liu, P., Kittelson, D. B., and McMurry, P. H. (1995). Particle Beam Mass Spectrometry of Submicron Particles Charged to Saturation in an Electron Beam, J. Aerosol Sci. 26(5):754-756. 